\title{
Segurança hemisférica: uma discussão sobre a validade e atualidade de seus mecanismos institucionais
}

\author{
Hemispheric Security: a discussion about the validity and the \\ contemporary of its institutional mechanisms
}

GRACIELA DE CONTI PAGLIAI*

Rev. Bras. Polít. Int. 49 (1): 26-42 [2006]

\section{Introdução}

Os mecanismos institucionais de segurança hemisférica criados na década de 1940 passaram a ter sua efetividade questionada pelos países membros na medida em que consideravam a perda de sua eficácia e utilidade em decorrência das alteraçôes pelas quais passou o sistema internacional nas últimas décadas. Tais modificações assinalaram a emergência de novos temas e percepções a serem levados em conta no cálculo dos atores. Dessa forma, houve uma mudança de entendimento relativa à agenda de segurança e, com isso, a necessidade de revisar os conceitos associados à segurança internacional.

Durante a bipolaridade os problemas de segurança internacional estavam, sobretudo, vinculados às questões militares estratégicas, em função da temática desta confrontação. Uma vez finda a Guerra Fria, novos temas e ameaças passaram a configurar a agenda internacional somando-se a novos atores para os quais devem ser consideradas variáveis outras que permitam explicar os fenômenos em questão e definir os instrumentos necessários e possíveis para a configuração da segurança internacional.

A reflexão aqui proposta, sobre os problemas contemporâneos de segurança internacional, considera dois aspectos em relação ao continente americano: o primeiro, é o da evolução e crise dos mecanismos institucionais de segurança e o segundo, o da emergência de uma agenda com temas de distinta importância para os atores da região.

A América Latina configura-se como uma região desnuclearizada, estável e com baixo nível de conflito, no entanto, é uma área que ainda enfrenta

\footnotetext{
* Mestre em Relações Internacionais pela Universidade Federal do Rio Grande do Sul - UFRGS e doutoranda em Relações Internacionais pela Universidade de Brasília - UnB (graciela.pagliari@gmail.com).
} 
problemas tradicionais de segurança de caráter fronteiriço, múltiplos conflitos de natureza diversificada e distintas vulnerabilidades, o que favorece a chamada segurança coletiva: instituiçōes débeis, ausência de mecanismos e foros multilaterais efetivos para agir de maneira eficiente perante os conflitos, e ausência de convergência de respostas comuns às ameaças e conflitos surgidos na região.

Os mecanismos de segurança hemisféricos foram implementados na década de 1940, portanto, planejados sob a ótica do conflito bipolar, com o objetivo de afastar a ameaça comunista da região e evitar subvençôes internas. Contudo, tais instrumentos tornaram-se crescentemente disfuncionais para atores como o Brasil que, no entanto, adotou ao longo dos anos 90, um baixo grau de prioridade e uma postura defensiva e reativa em relação ao esforço de transformação das condiçōes de exercício da segurança coletiva na região.

Os mecanismos institucionais devem ser capazes de produzir respostas a todos os tipos de ameaças à segurança no continente americano, inclusive às tradicionais que continuam presentes. Da mesma forma, precisam considerar que há uma grande disparidade de 'situações de segurança' nas sub-regiões da América Latina pois o término da Guerra Fria não trouxe o fim dos conflitos entre Estados, o que ocorreu foi uma certa relativização no seu dimensionamento uma vez que deixaram de ser vistos como parte do conflito ideológico LesteOeste. Com isso, o surgimento de uma nova agenda de segurança, na qual estão colocados novos riscos e ameaças, não exclui a agenda histórica de ameaça à segurança que enfrentam os países latino-americanos.

As turbulências surgidas internamente no hemisfério serviram para reativar as preocupações com relação à segurança, e, igualmente, no que diz respeito aos temas e prioridades hemisféricas, constata-se que, se por um lado, há uma agenda de discussão comum, por outro, existem assuntos discordantes - parcial ou integralmente. Desta forma, estes propósitos divergentes com relação à natureza e às implicações da nova agenda de segurança servem para obstruir possíveis respostas efetivas regionais.

As discussões em relação aos assuntos ligados à segurança internacional e, como seu resultado, as suas abordagens e definiçôes, produzem reflexos na agenda de política externa da América Latina e, da mesma forma, na formulação da política externa do Brasil. Por isso, a modificação da posição relativa dos principais países do hemisfério na sua inserção internacional e regional, bem como a emergência de novos temas e ameaças devem ser levados em conta na definição de sua agenda.

\section{Surgimento e crise dos mecanismos institucionais de segurança coletiva}

O sistema interamericano permaneceu com seus mecanismos coletivos de segurança inalterados, não tendo se adaptado às exigências decorrentes das mudanças no sistema internacional, especialmente depois da Guerra Fria. Pode- 
se considerar um leitmotiv que justificaria esta permanência no tempo na medida em que há, de um lado um sócio hegemônico - os EUA - capaz de estabelecer objetivos e desenvolver estratégias de longo prazo com solidez e, de outro, os países latino-americanos como sócios relativamente mais fracos.

As bases institucionais deste sistema foram estabelecidas em 1942, porém, a adoção de mecanismos comuns de segurança e defesa foi sendo delineada a partir de 1936, quando na Conferência Interamericana para a Manutenção da Paz, foi aprovada a Declaração de Princípios de Solidariedade e Cooperação Interamericana, com o intuito de considerar que cada ato suscetível de perturbar a paz da América seria um ato que afetaria cada uma e todas as repúblicas americanas.

$\mathrm{Na}$ Conferência do Rio de Janeiro em 1942, foi criada a Junta Interamericana de Defesa - JID, como órgão encarregado de planejar a defesa do hemisfério de agressões extra-hemisféricas, ou seja, caberia preparar gradualmente as repúblicas americanas para a defesa do continente, mediante a realização de estudos e a recomendação de medidas para este fim.

Em 1945 realizou-se em Chapultepec, no México, a Conferência sobre os Problemas da Guerra e da Paz, onde foi assinada a Ata de Chapultepec com uma declaração de "Assistência Recíproca e Solidariedade Americana", afirmando, deste modo, a solidariedade hemisférica. Nessa conferência, ficou efetivada a posição destinada à América Latina no pós-guerra, tendo em vista que, já em 1944, na Conferência de Dumbarton Oaks que visou a preparar o sistema internacional para a nova ordem, estabeleceu-se a natureza das organizações regionais, cabendo-lhes regular as disputas locais mediante a aprovação do Conselho de Segurança das Nações Unidas.

Contudo, esse dispositivo de defesa mútua contra agressão interna ou externa, deixava aos EUA a tarefa da defesa em âmbito militar, restando às demais Forças Armadas funções de manutenção da ordem interna política e social e auxílio às forças norte-americanas, sempre que se fizesse necessário, para facilitar as suas açôes. Já era política desenvolvida pelos EUA a de permitir que os países latino-americanos dispusessem de armamentos e munições apenas para repelir uma ameaça ou agressão sofrida, até a chegada das suas forças, que seriam, efetivamente, as garantidoras da segurança.

O ano de 1947 é marcado pelo lançamento da Doutrina Truman, do Plano Marshall e também pela assinatura do Tiar (Tratado Interamericano de Assistência Recíproca) ou Tratado do Rio. Pela Doutrina Truman, lançada em março, os EUA asseguravam que suas forças militares estariam sempre prontas a intervir em escala mundial, desde que fosse preciso defender um país aliado da agressão externa (da URSS) ou da subvenção interna, desencadeada pelo movimento comunista internacional. Posteriormente, em julho é lançado o Plano Marshall para a reconstrução da Europa Ocidental, devastada pela Segunda Guerra. Enquanto a recuperação da Europa contava com este plano para afastar a expansão do comunismo, a preocupação para com a América 
Latina estava direcionada a alguns governos e movimentos nacionalistas que deviam ser contidos, ou até mesmo, afastados.

Em setembro deste mesmo ano é assinado o Tiar. Nesse momento, as alianças da guerra estavam desfeitas e a URSS era considerada uma força agressiva em busca de expansão. O tratado configura-se, então, como um pacto de segurança e defesa coletiva, e, ao invés de acordos bilaterais, estabelece um acordo de assistência militar mútua multilateral contra ameaças externas; que recomenda aos Estados o uso de métodos pacíficos de solução de conflitos, condenado o uso da força ou o recurso à guerra. A sua idéia era a da formação de uma frente comum em caso de ataque a qualquer membro, invocando o exercício imanente da legítima defesa individual ou coletiva.

O fato, contudo, é que o Tiar representou muito mais um instrumento formal de defesa contra o avanço do comunismo do que propriamente um mecanismo que servisse para dissuadir agressōes externas. Ao longo do período de sua vigência, o mesmo foi invocado dezenove vezes, a maioria delas para casos na América Central e Caribe. Porém, foi aplicado efetivamente em oito ocasiōes, sendo que muitas outras intervenções ocorreram na América Latina no decorrer deste período, sem que, no entanto, se efetivassem sob o seu amparo.

Para muitos países, essa aliança americana perdera sentido após a Guerra das Malvinas em 1982, pois os EUA abstiveram-se de apoiar um país do continente, o que inviabilizou a invocação do Tiar como mecanismo de ajuda mútua do sistema interamericano. Nessa situação, o Brasil apoiou a Argentina, entretanto, não invocou os mecanismos de segurança coletiva, o que também não foi feito por nenhum outro país do continente.

A estruturação dos mecanismos de segurança e defesa do continente continuou em 1948 quando, na Nona Conferência Interamericana realizada em Bogotá, na Colômbia, formou-se a OEA - sucessora da União Pan-americana ${ }^{1}$ -, na qual ficaram consagrados os princípios fundamentais para a segurança coletiva. Foi estabelecido, como um de seus propósitos essenciais, garantir a paz e a segurança continentais. Originalmente, a OEA foi composta por 21 membros, no entanto, expandiu-se a ponto de todos os Estados americanos terem ratificado a $\mathrm{Carta}^{2}$, que foi reformada algumas vezes desde então, sendo que a insatisfação com o sistema interamericano foi uma constante em todas as iniciativas de reforma. Nesta mesma conferência foi celebrado o Pacto de Bogotá, visando a dar cumprimento ao artigo XXIII da Carta da OEA, pelo qual as partes acordaram em abster-se da ameaça, do uso da força ou de qualquer outro meio de coação para resolver as controvérsias, e em recorrer a todo tempo a procedimentos pacíficos.

\footnotetext{
${ }^{1}$ Em 1890 - na Primeira Conferência Internacional Americana - estabeleceu-se a União Internacional das Repúblicas Americanas mediante um Escritório Comercial das Repúblicas Americanas; em 1910, esta Organização viria a se converter em União Pan-americana e, depois, em OEA.

2 De todos os Estados americanos, somente Cuba não faz parte da OEA por ter sido excluída em 1962.
} 
O Colégio Interamericano de Defesa - CID, órgão da JID, foi criado em 1962, acrescentando um componente de instrução à especialidade de defesa e segurança no sistema interamericano, com o objetivo de preparar pessoal militar e funcionários civis para ocuparem cargos de responsabilidade no hemisfério.

Assim, estavam consolidados os mecanismos de segurança coletiva do sistema interamericano. Segundo esses instrumentos, as controvérsias e conflitos entre os países do continente deveriam ser resolvidos por meios pacíficos. Contudo, o Brasil manteve sua posição pela qual a defesa da segurança interna e da manutenção da paz de cada país do continente, bem como a defesa das suas instituições democráticas são de responsabilidade de seus governos e de suas Forças Armadas.

Desde os primeiros mecanismos de segurança, vários outros foram criados no continente americano, porém, esses instrumentos ou são bilaterais ou mesmo multilaterais, mas sem contar com a presença de todos os países que aderiram àqueles mecanismos iniciais. Especialmente ao longo dos anos 90, houve uma tentativa de revitalização do sistema interamericano mediante a criação de outros mecanismos sub-regionais de segurança na medida em que vários países questionavam a efetividade dos existentes. No entanto, essa tentativa de pôr em xeque a validade e a capacidade de operação desses mecanismos, em que pese ter mais força depois da Guerra Fria, já vinha ocorrendo desde os anos 60.

Muitos esforços bilaterais e sub-regionais vêm sendo feitos com o objetivo de alcançar uma concepção hemisférica de segurança, bem como para aperfeiçoar e ampliar as medidas de promoção da confiança mútua. Os esforços sub-regionais são importantes na concepção de um sistema de segurança, uma vez que expressam os contextos estratégicos peculiares de cada sub-região.

O diálogo regional estabelecido com vistas a revitalizar e fortalecer tais instituiçôes apontou para o fato de que, ao longo do tempo, os mecanismos foram perdendo força e validade na medida em que os EUA priorizaram uma agenda bilateral com os países do continente, retirando a importância e a capacidade de ação dos organismos multilaterais. Além disso, os Estados do hemisfério consideram que, além das ameaças tradicionais à segurança, novas ameaças e desafios de características mais complexas se apresentam, à medida que os problemas de segurança tornaram-se mais difusos.

\section{A agenda de segurança hemisférica no Pós-Guerra Fria}

A emergência de novas ameaças globais tem preocupado os países do hemisfério, pois as atuais questôes relativas à segurança partem de dimensões novas e mais complexas na ordem internacional do pós-Guerra Fria. Essa preocupação levou-os a discutir sobre a necessidade de revitalizar as instituiçóes de governo regionais - em que pese, para os países americanos, as instituiçóes terem uma influência muito limitada no que diz respeito ao comportamento 
do Estado. Os debates revelaram a necessidade de revitalização e fortalecimento das instituições de segurança, todavia, não foram efetivos no sentido de conduzir a um marco final de caráter ativo que indicasse claramente uma configuração das instituiçôes possível de atender às necessidades de segurança da região.

As discussões se desenvolveram mediante cúpulas e conferências no âmbito da OEA, assinalando para um fortalecimento das instituições regionais especialmente da própria OEA - sem, contudo, indicar o caminho das mesmas na configuração das relações interamericanas que estavam se desenhando. Esses encontros estiveram centrados em várias questóes chaves levando em conta os novos parâmetros regionais e mundiais. As discussões à luz dessas novas circunstâncias consideraram importantes questôes como: o fortalecimento da democracia na região como indispensável para a estabilidade, a paz e o desenvolvimento regionais; a promoção da prosperidade mediante a integração econômica e o livre comércio; medidas para avançar no fomento da confiança e da solução pacífica de controvérsias; a cooperação em matéria de defesa; o papel das Forças Armadas na promoção da paz, cooperação e segurança; o compromisso de preservar a paz e a segurança mediante a utilização efetiva dos instrumentos hemisféricos de resolução pacífica de controvérsias.

Pela Declaração de Bridgetown de 2002, lançada na XXXII Assembléia Geral da OEA, adotou-se uma abordagem multidimensional para a segurança hemisférica. No mesmo ano, os ministros de Defesa das Américas reunidos na sua $\mathrm{V}$ Conferência, reafirmaram o enfoque multidimensional da segurança devido ao complexo de ameaças e desafios que se colocaram aos Estados depois da Guerra Fria. Propuseram ainda que o sistema de segurança hemisférico fosse conformado por antigas e novas instituições de segurança baseadas na coletividade e cooperação, formando uma nova arquitetura flexível de segurança.

Por fim, as reflexões produzidas em âmbito da Comissão de Segurança Hemisférica da OEA, culminaram com uma Conferência Especial sobre Segurança que foi realizada em 2003, no México. Nela foram debatidas novas abordagens para a questão da segurança nas Américas, porém, não houve definição quanto ao surgimento de novos mecanismos de segurança e nem uma resposta única e coesa de todos os países do continente para as diversas ameaças. Os desafios que a região enfrenta manifestam-se politicamente em fragmentação, como se percebe pela Declaração da Conferência que ressalta o caráter de multidimensionalidade em relação aos aspectos de ameaça à segurança, e salienta, além das ameaças tradicionais, novas ameaças tais como o terrorismo, o crime organizado, as drogas, a corrupção e a lavagem de dinheiro, o tráfico de armas, os desastres naturais e de origem humana e o tráfico de seres humanos.

A declaração final reafirma os valores compartilhados e os enfoques comuns que são reconhecidos no hemisfério, tais como: o direito soberano de definir as prioridades nacionais de segurança e, com isso, definir as estratégias para fazer 
frente às ameaças à segurança; o respeito ao Direito Internacional e ao Estado de direito e à autoridade civil legalmente constituída; a proteção da pessoa humana como fundamento e razão de ser da segurança, portanto, a segurança do Estado e a segurança das pessoas reforçam-se mutuamente; a ampliação dos conceitos e as abordagens tradicionais para englobar as novas ameaças e as não-tradicionais que abrangem aspectos políticos, econômicos, sociais, de saúde e ambientais. Observa ainda a importância dos mecanismos existentes para enfrentar as ameaças tradicionais, mesmo que sejam de natureza diversa das novas ameaças e dos mecanismos de cooperação necessários para enfrentá-las. Além disso, ressalta o fato de que muitas das novas ameaças e desafios à segurança hemisférica são de natureza transnacional e podem requerer uma cooperação hemisférica adequada, por isso, a arquitetura de segurança deve ser flexível para incluir as particularidades de cada sub-região e de cada Estado.

Por outro lado, ao mesmo tempo em que a declaração reconhece a utilidade e a importância de instrumentos como o Tiar e o Pacto de Bogotá, sugere que o processo de exame e avaliação desses mecanismos deve continuar, levando-se em conta as realidades de segurança do hemisfério e a natureza diversa de ameaças tradicionais e não-tradicionais. Reafirma ainda a necessidade dos Estados se empenharem na promoção da paz e da estabilidade internacional, apoiando os regimes de desarmamento e não-proliferação de armas de destruição em massa e controle de armamentos. O terrorismo foi o tema que ganhou grande destaque na Declaração Final, evidenciando-se a intenção de prevenir, punir e eliminá-lo, mediante repressão ao seu financiamento e impedimento quanto à circulação internacional de terroristas.

No entanto, como se percebe no exame dos principais assuntos da agenda de segurança, a aparente multidimensionalidade dos temas consagrados na conferência não permite concluir que se estabeleceu uma agenda multidimensional real. Isso porque não se fixou um plano de ação cooperativo e nem há uma unidade de idéias e açóes entre os vários países do hemisfério. Apesar de os problemas e ameaças serem distintos para os Estados, a multidimensionalidade resultante não deixa de ser uma nova forma de reiterar a supremacia norte-americana no continente, pois diferentes países priorizam estratégias, mecanismos institucionais e temas de segurança diversos, e as principais estratégias e respostas são capitaneadas pelos EUA.

A discussão na conferência conseguiu ser, de certa forma, mais abrangente por incluir questôes outras que não apenas as impostas pela agenda norteamericana. A importância em debater a revitalização dos mecanismos institucionais e temas prioritários de segurança foi ressaltada pela grande maioria dos membros da OEA; contudo, diversos países - dentre eles o Brasil consideram que as variáveis estratégicas e as ameaças à segurança não são homogêneas para todo o hemisfério. Dessa forma, parece salutar que as discussões e reuniões desenvolvidas pela Comissão de Segurança Hemisférica 
tenham mostrado os anseios e as necessidades de segurança de cada país, resultando em uma declaração que considera as preocupações de todos os Estados, porém, como não foram incorporados mecanismos de respostas a essas preocupações ou ameaças, resta de pouca utilidade a fixação ou menção de todas as ameaças na declaração. Isso porque essa multidimensionalidade não modifica a relação de hegemonia dos EUA com os demais países do hemisfério.

Segundo Hirst $(2003)^{3}$, os novos temas de segurança decorrem, em grande medida, de um recuo da atuação estatal e a importância dos mesmos pode ser reduzida ou aumentada toda vez que um conjunto novo de ameaças emerge na agenda de segurança global. Assim, enquanto as questôes de prejuízos ambientais e migrações são consideradas agora como problemas de segurança humana, o narcotráfico na "supernova" agenda está identificado como parte da luta contra o terrorismo. Para a autora, a mobilidade entre agendas não apenas diz respeito à natureza das ameaças mesmas mas também aos atores envolvidos.

As proposições apresentadas na Declaração da Conferência remetem a uma agenda atual de segurança na qual as questóes da Guerra Fria assumiram uma outra dimensão. As noções de segurança se alteraram de maneira fundamental, especialmente aquelas que dizem respeito às ameaças internacionais, por isso, ultimamente outras estão sendo eleitas como as mais importantes. Conforme Villagra Delgado $(2003)^{4}$, há um novo cenário estratégico em nosso continente decorrente de uma combinação de fatores como o desenvolvimento de ações cooperativas em matéria de segurança e defesa que superaram várias hipóteses de conflito; importantes conseqüências de fenômenos socioeconômicos que derivam das denominadas novas ameaças, e, talvez a mais importante manifestação destas novas formas de violência: os atentados terroristas contra os EUA em 2001. Estas questôes serviram para colocar o continente em um novo cenário estratégico.

As agendas de segurança dos países do continente não coincidem em todos os pontos e a nova agenda proposta apresenta, ao mesmo tempo, possibilidades e obstáculos para a configuração de uma agenda de segurança que seja plenamente compartilhada entre os países do hemisfério. Consoante o enfoque de essencialidade na revitalização das instituições hemisféricas, os países latino-americanos compartilhariam de uma espécie de agenda comum, no entanto, como referido anteriormente, esta idéia de consenso não se estende à totalidade da agenda.

\footnotetext{
${ }^{3}$ HIRST, Monica. Seguridad regional en las Américas. In: GRABENDORFF, Wolf. La seguridad regional en las Américas. Bogotá: Cerec, 2003. p. 25-80.

${ }^{4}$ VILLAGRA DELGADO, Pedro. Nuevo paradigma de seguridad hemisférica. Foreign Affairs En Español, México, v.3, n.4, Oct.-dic. 2003.
} 
A mudança na percepção da agenda de segurança no pós-Guerra Fria não retirou a importância das questóes de segurança estratégica, conforme referido por Sato $(2000)^{5}$. O que ocorreu foi que elas assumiram uma nova dimensão ao serem vistas de modo integrado com os novos temas da agenda de segurança internacional. Ainda, segundo o autor, a mudança desencadeada com o fim da Guerra Fria assumiu um papel importante, mas essa modificação não apareceu de modo tão evidente na composição dessa agenda, e sim, no grau da importância que passou a ser atribuída às diversas questôes porque a maior parte delas já existia, o que sofreu alteração foi o modo de percebê-las.

A dificuldade em se fixar uma agenda comum de segurança está diretamente ligada ao papel de sócio hegemônico que os EUA desempenham no continente. Assim, para Hurrell $(1998)^{6}$, os divergentes propósitos entre os Estados americanos com relação à natureza e implicações da nova agenda de segurança refletem-se em termos políticos e impedem efetivas respostas regionais. Entretanto, para Hirst $(1995)^{7}$, a subordinação estrutural à presença hegemônica dos EUA na América Latina tem servido para neutralizar o poderio econômico e militar desigual entre os Estados latino-americanos. Contudo, essa sujeição não tem impedido os países da região de desenvolverem políticas de defesa divergentes que, em algumas ocasiōes, foram levadas adiante. A superioridade norte-americana que se mostra no sistema internacional no pósGuerra Fria tem trazido inúmeras implicaçōes para a agenda de segurança do hemisfério, inclusive, os EUA se valeram dos diversos desacordos referentes às questôes de segurança entre distintos países do hemisfério e passaram a negociar acordos bilaterais em detrimento da multilateralidade.

Para os países da região, o conteúdo e o significado das ameaças à sua segurança são indicados a partir da análise de sua posição relativa na balança de poder hemisférica; isto é, a pauta pode variar de acordo com os interesses em jogo. Assim sendo, a multidimensionalidade da agenda não se traduz em respostas aos problemas e ameaças dos diversos países do hemisfério, mas sim, na reiteração da relação EUA - América Latina ao caracterizar, com uma nova roupagem, esta relação na medida em que os principais temas da agenda continental continuam a ser os indicados pelos EUA.

Dessa forma, dois temas que foram destacados nas discussões e na Declaração da Conferência - terrorismo e narcotráfico - são apontados como extremamente importantes para os EUA e sobre os quais possuem imenso poder de arregimentação. Esta agenda é eminentemente de segurança nacional

\footnotetext{
5 SATO, Eiiti. A agenda internacional depois da Guerra Fria: novos temas e novas percepçōes. Revista Brasileira de Política Internacional, Brasília, ano 43, n. 1, p. 138-169, 2000.

${ }^{6}$ HURRELL, Andrew. Latin America's New Security Agenda. International Affairs, v. 74, n 3, p. 529 546, July 1998.

7 HIRST, Mônica. Obstáculos ao governo regional no hemisfério ocidental: velho regionalismo na nova ordem mundial. Revista Politica Externa, São Paulo, v. 4, n 2, p. 95-122, set. 1995.
} 
e difere das principais questóes apontadas pelos Estados do continente. Além disso, o sistema regional tem se caracterizado pelo desmembramento da agenda em subsistemas. Assim, enquanto a violência ressurge em alguns países da América Latina com a conseqüente militarização da sociedade, a América Central se caracteriza pela tendência a desmilitarização e ao desarme, e o Cone Sul pela cooperação das Forças Armadas decorrente da integração e da restauração democrática.

O narcotráfico na região andina é uma das questôes de segurança mais importantes das últimas décadas nas Américas. A Colômbia, um dos países mais afetados, adotou o Plano Colômbia para combater o narcotráfico. O mesmo foi traçado com o objetivo de alcançar a paz; erradicar as drogas; promover um desenvolvimento alternativo, os direitos humanos e uma reforma judicial. Mas acabou assumindo um caráter de militarização no combate às drogas e, além da Colômbia, poucos são os outros países da região que aceitam a idéia do 'narcoterror', ou seja, de que há uma ligação entre o narcotráfico e o terrorismo. Para alguns autores, a política norte-americana para as drogas converteu-se na maior fonte de inseguridade para a regiāo, tendo em vista que os EUA consideram-na como questão de segurança nacional.

A questão da instabilidade na Colômbia e da transposição de suas fronteiras alcançando seus vizinhos, evoca a importância da estabilidade regional. No limite, a segurança de um país não pode estar baseada em vizinhos não estáveis, tendo em vista que as ameaças não se atêm às fronteiras físicas. Além disso, os países latino-americanos não têm políticas de Estado para controlar a escalada da violência, nem instituições suficientemente fortes e enfrentam ainda uma fragilidade democrática. No caso da Colômbia, as drogas têm uma conotação de maior gravidade porque fomentam guerrilhas internas, incentivando a guerra por território, na qual a população civil é o perdedor imediato.

As diferentes necessidades de segurança da região indicam que uma resposta regional efetiva quanto à nova agenda de segurança não é uma tarefa simples, pois há pouco consenso acerca do que representa ou implica a nova agenda. Assim, ao passo que as ameaças tradicionais são sentidas por todos os países ao mesmo tempo, as novas ameaças minam o consenso regional uma vez que há parâmetros diferentes para caracterizar o interesse dos Estados e o apropriado papel das Forças Armadas. Além disso, segundo Hurrell $(1998)^{8}$, a interdependência entre os Estados da região é muito forte, o que contribui para aumentar os níveis de vulnerabilidade. Por outro lado, o poder na região é extremamente desigual sendo a maior marca disso a desigualdade entre os EUA e os demais países do hemisfério. Portanto, a combinação entre a interdependência e a desigualdade de poder dificulta a estruturação de um arranjo de segurança regional.

${ }^{8}$ HURRELL, Andrew. Op. cit. 


\section{A política externa brasileira em relação à segurança hemisférica}

O ponto central desta seção é refletir acerca dos desafios e constrangimentos colocados no pós-Guerra Fria para a política externa brasileira em relação as suas posições e participação nos mecanismos de segurança hemisférica e como isso se reflete na sua autonomia na tomada de decisóes. Note-se que no final dos anos 70 e início dos 80 , começou um processo de aproximação brasileira com os países americanos, especialmente com os vizinhos do Prata. Após esse acercamento, começaram as discussões quanto à atualidade e eficácia dos mecanismos de segurança hemisféricos. As mudanças no sistema internacional, que alteraram as prioridades dos EUA e geraram novas demandas por segurança, de certa forma, agiram no aumento da interdependência entre os países da América Latina e, ensejaram uma discussão da política externa brasileira para a segurança, no sentido de que os padrões da Guerra Fria não se mostram como os mais adequados para enfrentar os novos problemas e preocupações de segurança.

As demandas atuais não são as mesmas que motivaram a formação dos mecanismos de segurança nos anos 40. Questões como combate ao narcotráfico, ao crime organizado e ao tráfico ilícito de armas despontam atualmente na agenda, especialmente ao se considerar uma política entre o Brasil e os países andinos. Esses problemas, além de afetar a segurança nacional, produzem reflexos para a segurança humana e pública. Muito mais do que a necessidade de ação militar são questóes que precisam ser combatidas com políticas públicas de erradicação das desigualdades sociais, que geram um quadro de pobreza extrema e que permitem a propagação de crimes conexos como a corrupção e lavagem de dinheiro.

No pós-Guerra Fria o Brasil tem pautado sua política pela defesa da democracia e apoio à criação de mecanismos para garanti-la, como elemento fundamental para a manutenção da segurança. Assim, o governo brasileiro desenvolveu um relativo distanciamento da política da superpotência, não se envolvendo nas iniciativas de segurança internacional protagonizadas pela mesma. Tanto nos níveis regional quanto global, o Brasil tem procurado agir para contrabalançar a hegemonia norte-americana "reforçando a correlação entre o status de potência regional e o cálculo de opções internacionais", segundo análise de Oliveira e Onuki (2000, p. 110) ${ }^{9}$. Nesse sentido, sua ação tem sido de forte adesão aos regimes internacionais de segurança $\mathrm{a}^{10}$ e também de adoção

\footnotetext{
9 OLIVEIRA, Amâncio Jorge; ONUKI, JANINA. Brasil, Mercosul e a segurança regional. Revista Brasileira de Política Internacional, Brasília, ano 43, n 2, p. 108-129, 2000.

10 O Brasil ratificou o Tratado de Tlatelolco (1994), o TNP (1998), o Acordo Quadripartite de Salvaguardas Nucleares com a Argentina (ABACC e AIEA, 1994), e no plano global aderiu ao Regime de Controle de Tecnologia de Mísseis (MTCR, 1995), ao Grupo de Supridores Nucleares (NSG, 1996), e a Organização para a Proibição das Armas Nucleares (Opaq, 1996).
} 
de uma política de prioridade da América do Sul, visando a articulação de um espaço de atuação sul-americano para, por meio dele, formar um eixo de confiança militar e política.

O Brasil e os demais países da região têm ressaltado seus compromissos com a manutenção e o aprofundamento das instituições democráticas. No entanto, a formulação dos objetivos da política externa brasileira não pode deixar de considerar as interpretações discordantes do cenário internacional no pós-Guerra Fria pelos sul-americanos, pois estas ensejam distintas prioridades de política exterior, com conseqüências inevitáveis sobre as políticas de segurança na região.

O tema da segurança readquiriu proeminência na OEA depois da Guerra Fria, passando do foco da ameaça externa para interna e de eventuais conflitos entre Estados do hemisfério. Enquanto o sistema esteve moldado pela rigidez do mundo bipolar, houve dificuldade ou impossibilidade de formar outros mecanismos de segurança coletiva. Além disso, a potência hegemônica no continente tinha estabilizado-o como sua zona de influência e não demonstrava interesse na formação ou aprofundamento dos mecanismos de segurança coletiva. Os EUA estavam mais preocupados em preservar a sua segurança, ao assegurar o seu domínio na região, do que com a segurança dos demais membros. Somente nos anos 1990 novos mecanismos ${ }^{11}$ foram criados entre os países das Américas. Esses instrumentos seguiram um caráter regional de consolidação das democracias, aprofundamento da cooperação, consolidação de medidas de confiança mútua, e indicação de desenvolvimento de uma pauta alusiva às necessidades e preocupações de seus membros.

A despeito de ter estabelecido como pilar de sua política externa o fortalecimento da integração na América do Sul, o Brasil tem desenvolvido uma política pendular em relação às instituições e acordos dos quais é parte. Conforme Borges (2001) ${ }^{12}$, o Brasil trabalha com uma política mais ou menos voltada para a consolidação e aprofundamento das instituições ou acordos relacionados àquele mecanismo, segundo seu interesse de poder. Ou seja, sua política privilegia o aprofundamento dos acordos ou da institucionalização em mecanismos nos quais detém uma parcela relativa menor de poder, ao passo que naqueles nos quais a sua parcela de poder é maior, sua proposição é de resguardar o exercício do seu poder, mediante um comprometimento menor. Este posicionamento leva em conta a variação de poder e a influência brasileira em cada um desses processos e está diretamente ligado ao peso do poder que a

\footnotetext{
${ }^{11}$ Dentre esses mecanismos pode-se citar a Declaração Política do Mercosul, Bolívia e Chile como Zona de Paz de 1999, que visa a contribuir para os esforços de revitalização do sistema interamericano de maneira a permitir que as especificidades e potenciais ameaças de cada região sejam observadas e contempladas no sistema de segurança.

12 BORGES, Bruno de Moura. O Brasil no Grupo do Rio: dilemas e perspectivas. In: ENCONTRO ANUAL DA ANPOCS, 25, 2001, Caxambu, MG. Anais... Caxambu, 2001.
} 
potência hegemônica exerce ao participar ou não do mecanismo. Dessa forma, a ação política do Brasil tem sido a de explorar eventuais margens de manobra em cada uma das áreas de seu interesse.

Relativamente às discussões sobre a revitalização das instituições do sistema interamericano, a posição brasileira destacava que as variáveis estratégicas e as ameaças à segurança não seriam homogêneas para todo o hemisfério, dessa forma, na adoção de um novo conceito de segurança seria salutar levar em conta as necessidades específicas de cada país sem desconsiderar, contudo, os princípios de soberania e não-ingerência. Assim, a Declaração da Conferência deveria considerar alguns aspectos essenciais ${ }^{13}$ : o primeiro, relacionado à "segurança tradicional" ou "defesa clássica"; o segundo, relacionado às "ameaças não-tradicionais" que provêm de atores não-estatais, mas que constituem perigo real e imediato para o Estado, tais como o narcotráfico, o terrorismo e o tráfico ilícito de armas; o terceiro, relacionado às "ameaças em sentido amplo", ou seja, aqui não estão contempladas nem as ameaças tradicionais nem as nãotradicionais, mas, muitas vezes estes aspectos são apresentados como causas estruturais dos problemas de segurança de grande parte dos países da região. São eles: pobreza crítica, os desastres naturais, saúde, meio ambiente, comércio e mais uma quantidade de fatores que podem afetar os níveis de segurança dos Estados. A soma destes fatores às ameaças tradicionais e não-tradicionais dão à segurança hemisférica um caráter mais abrangente ou "multidimensional".

Esse enfoque de segurança multidimensional adotado pelo hemisfério reflete uma agenda plural e uma manifestação de vontade política dos Estadosmembro de fortalecer um regime de segurança hemisférico que atenda às condições geográficas, políticas, sociais, culturais e econômicas de cada país ou região, e as necessidades de cada Estado, da maneira que seja mais adequada, contribuindo assim, para aumentar a segurança na região. Certos valores, já constantes na Carta da OEA, são compartilhados por todos como a paz, a estabilidade, a solidariedade continental, o respeito à soberania e a não-ingerência, a promoção da democracia e da cooperação, a solução pacífica de controvérsias. Contudo, existem diferenças de percepções entre as realidades político-estratégicas de cada região que precisam ser consideradas e respeitadas. As realidades diversas que, em muitos casos, apresentam fatores de desestabilidade ou crises políticas, permitem visualizar a fragilidade da região. Dessa forma, para alguns autores, o Brasil deveria rever a tese da estabilidade estratégica no entorno regional, em face da alta probabilidade de desestabilização.

O Brasil se opunha à introdução de instâncias militares no sistema interamericano, defendendo a idéia de que a JID deveria manter sua relação com a OEA nos termos estabelecidos e não ser transformada numa espécie de

13 Estes aspectos foram enfatizados pelo Embaixador Valter Pecly Moreira, Representante do Brasil junto à $\mathrm{CSH}$, em reuniāo a 5 de novembro de 2002. 
braço armado dos mecanismos hemisféricos. Quer dizer, a JID permaneceria como órgão de assessoramento técnico-militar e não assumiria funções operacionais. Seu entendimento é de que os Estados precisam manter forças internas para ter capacidade de sobreviver como unidades soberanas independentes uma vez que o sistema internacional apresenta instabilidades para as quais os Estados devem estar preparados para dar respostas efetivas. Assim, as Forças Armadas precisam manter a agilidade e uma rápida capacidade de resposta para eventual necessidade de contrapor uma agressão e, soberanamente, cada país das Américas deve poder definir as prioridades e maneiras de empregar as suas Forças Armadas.

A posição do Brasil - diferentemente dos seus vizinhos andinos e dos EUA - tem sido contrária à militarização, ou seja, atribuir às Forças Armadas o envolvimento em atividades que não têm sido suas tradicionalmente como, por exemplo, o combate às drogas. Este posicionamento encontra justificativa na medida em que o Brasil considera que o crime organizado e seus efeitos deveriam ser combatidos pelas forças policiais. No entanto, esse problema gera preocupações em relação à segurança pública, pois apresenta conseqüências políticas, econômicas e sociais para todos os estados da região.

As questóes consideradas na agenda como ligadas à segurança pública são as preocupações de destaque entre os países das Américas. Conforme apresentado por Bailey at al. $(2001)^{14}$, a segurança pública engloba a segurança das pessoas e de seus bens contra agressões ou ameaças internas ou externas, a segurança física ou psicológica contra ameaças ou agressôes físicas de outros, a segurança do cidadão contra coerção ilegal de agentes do Estado e a proteção às instituiçôes democráticas. Para responder às ameaças à segurança pública, os governos empregam esforços para melhorar a cooperação entre Forças de Segurança ${ }^{15}$ e aprofundar a cooperação internacional.

Segundo essa concepção, o Estado tem a responsabilidade de combater o crime com os recursos humanos e materiais de suas forças policiais - sem incluir as Forças Armadas - para salvaguardar a liberdade, a vida e a propriedade, os direitos e garantias do povo, e as instituições de acordo com suas Constituições nacionais. E, visando eliminar os problemas de segurança pública, fazer interagir, dentro do sistema democrático, as instituições e as pessoas. O Brasil e países como Argentina, Bolívia, Chile e Colômbia apresentaram, nos últimos anos, estratégias para lidar com as questôes relacionadas à segurança pública. Dentro das preocupações de segurança, o governo brasileiro tem ressaltado também questôes econômico-sociais, que se enquadram como preocupação de segurança pública. $\mathrm{O}$ ministro Celso Amorim

${ }^{14}$ BAILEY, John. New Security Challenges in the South-North Dialog. In: BAILEY, John (Ed.) Public Security in the Americas: New Challenges in the South-North Dialog: Working Paper. Georgetown University, 2001.

15 Estas forças podem incluir Polícia Civil, Inteligência, Forças Militares e Agências de Controle de Fronteiras. 
ressaltou que "não existe segurança política sem segurança econômica, e não há segurança econômica sustentável sem justiça social"16.

Todavia, os países da América do Sul têm sido incapazes de enfrentar de maneira eficaz esses problemas, como salienta Oliveira $(2004)^{17}$; fator que gera vulnerabilidade também em função de componentes sociológicos como a fome, a pobreza extrema, delitos transnacionais e a fragilidade de alguns sistemas democráticos. Potencialmente, pode se tornar uma ameaça aos Estados latinoamericanos na medida em que as suas estabilidades podem ser rompidas por conflitos internos ou transnacionais, como parte das novas ameaças à segurança dos Estados. Por isso, conforme análise de Estévez (BAILEY at al., 2001) ${ }^{18}$, as vulnerabilidades que ameaçam as democracias da região não podem ser desconsideradas na análise das questões de segurança; eis que os problemas de criminalidade e violência impossibilitam a estruturação de uma cultura democrática, causando instabilidade nos países da região.

Tal vulnerabilidade também fica demonstrada em relação à Amazônia fator que é compartilhado com os vizinhos brasileiros - pois é uma área que apresenta, de uma maneira geral, problemas associados à desocupação, a escassa presença do Estado, e inúmeros problemas sociais causados por essa ausência, desenvolvendo um ambiente favorável à implantação e florescimento de atividades à margem da legalidade, tais como a questão das drogas e do tráfico de armas, segundo Vaz (2002) ${ }^{19}$.

Apesar da grande maioria dos países americanos compartilhar esses problemas, pouca coisa em comum tem sido feita para resolvê-los. O Brasil tem demonstrado preocupação com a estabilidade na América do Sul, mas ela somente será possível se as ações forem desenvolvidas de maneira multilateral, sobretudo, articulando o espaço sul-americano. Isso porque, no caso de Estados que não possuem capacidade operacional adequada, a criação de estruturas comuns é uma alternativa a ser aprofundada.

$\mathrm{O}$ questionamento a ser feito é de que forma essa solução vai ser pensada no hemisfério. Da mesma maneira, a pluralidade da agenda reflete as inquietações de segurança de todos os Estados-membro do sistema interamericano, porém, como será possível equacionar esses temas com instrumentos adequados de cooperação se não são as prioridades da potência

\footnotetext{
16 Discurso proferido na Conferência Especial sobre Segurança no México, 2003.

17 OLIVEIRA, Eliézer Rizzo de. O Brasil diante dos desafios internacionais em matéria de segurança e defesa: um enfoque hemisférico. In: PINTO, J. R. de Almeida; ROCHA, Antônio Jorge Ramalho da; SILVA, R. Doring Pinho da (Org). O Brasil no Cenário Internacional de Defesa e Segurança. Brasília: Ministério da Defesa, Secretaria de Estudos e de Cooperação, 2004. p. 89 - 101.

18 ESTÉVEZ, Eduardo E. Public and Citizen Security in South America: Trends, Controversies and Proposals. In: BAILEY, John (Ed.) Public Security in the Americas: New Challenges in the South-North Dialog: Working Paper. Georgetown University, 2001.

${ }_{19}$ VAZ, Alcides Costa. Desafios e questōes de segurança nas relaçôes do Brasil com os países andinos. In: Research and Education in Defense and Security Studies - REDES, 2002, Brasília.
} 
hegemônica? Os mecanismos sub-regionais talvez sejam uma resposta positiva, no entanto, as Américas não compartilham uma agenda única e esta é uma dificuldade adicional. Por isso, há um prejuízo à interlocução entre os Estados do hemisfério, em decorrência de suas percepções distintas; assim sendo, mais premente se torna a necessidade de construir um ponto comum como referência ${ }^{20}$.

\section{Conclusão}

Procurou-se analisar neste trabalho o significado e a evolução dos mecanismos de segurança hemisférica, bem como o posicionamento e os desafios apresentados ao Brasil em relação a estes mecanismos, e frente à nova agenda de segurança hemisférica.

A adesão brasileira às instituições de segurança hemisféricas ou regionais no pós-Guerra Fria tem sido estabelecida na medida do seu peso relativo na balança de poder do subsistema americano, dessa forma, leva em conta os cálculos de custo-benefício dessa participação, considerando o grau de autonomia da política externa brasileira e a possibilidade de resistir à supremacia norte-americana. O Brasil parece ter se preocupado em influenciar mais diretamente a sua sub-região, e mostra-se mais disposto a institucionalizar os mecanismos nos quais o seu poder relativo é menor.

Não obstante essa relação de poder e dos cálculos a ela correlatos, a evolução político-econômica da década de 1990 fez com que as várias regiōes do hemisfério e alguns países mais importantes priorizassem diferentes estratégias, mecanismos institucionais e temas de segurança. Neste período, diversos mecanismos subregionais foram sendo criados e - a despeito da retórica de que eles não fragmentam o continente, mas promovem sua união resguardando as diversidades de segurança de cada uma das regiōes - servem, em última instância, para indicar uma regionalização da agenda e uma carência dos mecanismos existentes em unir o hemisfério em torno deles.

Embora os problemas de segurança e as diferentes ameaças dos diversos países tenham sido contempladas num conceito amplo na Declaração da Conferência do México, não foram criados mecanismos capazes de responder a estas ameaças. Portanto, mais do que considerar as necessidades de segurança dos países do hemisfério, a nova agenda representa, até aqui, uma tentativa de acomodar descontentamentos sem alterar a relação de supremacia dos EUA no continente. Apesar dessa agenda parecer mais democrática porque considera em sua composição as distintas preocupaçôes com segurança, ela não estabeleceu mecanismos de resposta às necessidades de segurança dos diversos países.

20 Segundo o embaixador Valter Pecly Moreira, Documento OEA/Ser.G CP/CSH/INF.16/02 add. 4, nov.2002. 
A despeito do papel marginal da América Latina na agenda internacional global dos EUA, os efeitos das suas políticas de segurança se refletem no continente. As prioridades como o terrorismo e o combate às drogas têm prevalecido na agenda dos EUA, expandindo-se para toda a região especialmente os Andes - e vêm desencadeando respostas unilaterais que ocasionam uma ainda maior fragmentação política. As diferentes prioridades e necessidades de segurança geram múltiplas agendas, por isso, é muito difícil encontrar uma resposta efetiva comum que sirva para todos os dilemas de segurança apresentados na região.

A aproximação do Brasil com a América do Sul resulta de uma tentativa de integrar o espaço sul-americano e permitir uma certa autonomia em relação aos EUA. A adoção de uma agenda de segurança comum entre esses países, permitiria, potencialmente, a criação de uma comunidade de segurança. Mas, tanto no nível regional quanto sub-regional, o Brasil não tem agido de maneira suficiente para unir a América do Sul em torno de uma agenda de segurança comum. Assim, em que pese o seu apoio às medidas de fomento da confiança com os países do Cone Sul e a sua vontade manifesta de integração da América do Sul, as suas ações na sub-região não visam à promoção de arranjos comuns de segurança.

Recebido em 27 de abril de 2006 Aprovado em 20 de junho de 2006

\section{Resumo}

As profundas mudanças que ocorreram no sistema internacional com o término da Guerra Fria provocaram revisão de seus padrões, em especial, dos parâmetros de segurança coletiva hemisférica baseados em mecanismos que visavam garantir a segurança dos Estados-membro mediante a legítima defesa individual ou coletiva. Os Estados-membros indicaram a necessidade de repensar estes arranjos de maneira que os mecanismos estivessem apropriados para enfrentar as novas e difusas ameaças à segurança hemisférica.

\section{Abstract}

The deep changes that occurred in the international system with the end of the Cold War provoked the revision of theirs patterns, mainly the hemispheric collective security parameters based on mechanisms that aimed at assuring the security of the member states by means of inherent right of individual or collective self-defense. The member states pointed out the necessity of rethinking these arrangements so that the mechanisms could be suitable to face new and diffuse threatens to hemispheric security.

Palavras-chave: política externa do Brasil, segurança hemisférica, Organização dos Estados Americanos.

Key words: Brazilian foreign policy, hemispheric security, Organization of American States. 